\title{
Prediction of Creep Lifetime for Butt-Welded Joint of \\ Type 304 Stainless Steel by Finite Element Method Incorporating Damage Variable
}

\author{
By Junichi KINUGAWA**, Masayoshi YAMAZAKI**, Hiromichi HONGO**, \\ Takashi WATANABE*** and Yoshio MONMA**
}

\begin{abstract}
A computational method of predicting creep lifetime is presented for welded joints.

In the present method, time-incremental computations of stress by a finite element method and simultaneous cumulations of a variable as a measure of creep damage are reiterated up to the critical time for the cumulative value to exceed a specified limit. This critical time is regarded as the creep lifetime.

A butt-welded joint of $50 \mathrm{~mm}$ thick Type 304 stainless steel was prepared by SAW with depositing a 308 wire. Specimens cut from the joint were subjected to creep tests at $823 \mathrm{~K}$ under applied stresses of 200 to $300 \mathrm{MPa}$. The obtained data was compared with the computations.

The comparison showed that the creep lifetime of the joint predicted from the computations is within the factor of two (one half to two times) of that measured.
\end{abstract}

Key Words : Creep, Damage, Lifetime, Finite element method, Welded joint, Stainless steel

\section{Introduction}

During the past few decades, ever increasing demands on higher efficiency in thermal power plants and chemical plants have been supplied by scaling up their sizes with adopting welding fabrication and by elevating their metal temperatures toward creep ranges. In view of these trends, predicting creep lifetime of welded joints with high accuracy can be one of the keys to ensure the integrity and continued functioning of structural components.

Creep-rupture tests provide the most direct information of creep lifetime. For welded joints, however, the tests by using full-scale specimens are often impracticable owing to the limited capacities of conventional testing machines. On the other hand, the data obtained by using smallscale specimens is not always helpful for us to make surely conservative decisions, because the size effect of specimens is inevitable in testing joints with a geometrical discontinuity and/or metallurgical heterogeneity ${ }^{1}$.

These limitations and the long time involved in creep testing, although not being particular in testing welded joints, more or less require computational analyses.

To date, many computational analyses have been reported for creeping structures or components ${ }^{2-7}$. But, most of the reports deal only with computations, and especially for welded joints, very few refer to the accuracy through comparing computations with measurements.

The present paper deals with a computational method of predicting creep lifetime of welded joints. In this method, computations of stress in creeping joints by a finite element method $(\mathrm{FEM})^{2)}$ are coupled with cumulations of a variable as a measure of creep damage ${ }^{8)}$.

Comparison between the predicted and actually measured lifetime is also made for a butt-welded joint of Type 304 stainless steel.

\section{Method of Predicting Creep Lifetime}

In the present method, any creep damage is quantified by using a "damage variable".

\subsection{Damage Variable and Damage Law}

Empirically, most of creep-rupture data can be approximated by a straight line in a log-log plot (power law) of applied stress $\sigma$ versus time-torupture $t_{\mathrm{r}}$ such that

$$
\log _{10} \sigma=\mathrm{A} \log _{10} \mathrm{t}_{\mathrm{r}}+\mathrm{B}
$$

\footnotetext{
* Received: 17 March, 1994.

** Member, National Research Institute for Metals, 1-2-1 Sengen, Tsukuba-city 305, Japan

*** National Research Institute for Metals, 1-2-1 Sengen, Tsukuba-city 305, Japan
} 
where $\mathrm{A}$ and $\mathrm{B}$ are constants.

If so, by analogy, the stress dependence of the evolution of creep damage can be also expressed in the form of a power law ${ }^{8)}$

$$
\dot{\omega}=\mathrm{C}\left\{\sigma^{\mu} /(1-\omega)^{\mu}\right\} \text {, }
$$

where $\omega$ is a state variable to quantify the current state of creep damage, which is normalized to increase from 0 in a virgin state of materials at time $t=0$ to 1 in a completely damaged state at $\mathrm{t}=\mathrm{t}_{\mathrm{r}}$, and $\dot{\omega}$ is the time rate-of-change of $\omega$, while C, $\mu$ and $\nu$ are material constants. The variable $\omega$ (which is hereafter referred to as "damage variable") is introduced from a purely phenomenological point of view ${ }^{8)}$. The term $1 /(1-\omega)^{\nu}$ expresses that any creep damage may accelerate itself.

Separation of the variables $\omega$ and $\sigma$ in Eq. (2), and then, integration under the initial condition of $\omega=0$ at $t=0$ and the final condition of $\omega=1$ at $\mathrm{t}=\mathrm{t}_{\mathrm{r}}$ yields $^{9 \mathrm{j}}$

$$
\int_{0}^{1}(1-\omega)^{\nu} \mathrm{d} \omega=1 /(\nu+1)=\mathrm{C} \int_{0}^{\mathrm{tr}} \sigma^{\mu} \mathrm{dt} .
$$

In case an applied stress $\sigma$ is kept at a fixed level during creep-rupture testing, we obtain the timeto-rupture

$$
\mathrm{t}_{\mathrm{r}}=1 /\left\{\mathrm{C} \sigma^{\mu}(\nu+1)\right\} \text {. }
$$

Comparison of Eq. (1) and the common logarithm of Eq. (3) yields

$$
\mu=-1 / \mathrm{A} \text { and } \mathrm{C}(\nu+1)=10^{\mathrm{B} / \mathrm{A}} \text {. }
$$

Thus, the value of $\mu$ can be readily found only by making the empirical equation (1) from creeprupture data. Determination of each value of $\mathrm{C}$ and $\nu$, however, requires not only creep-rupture data but also data of creep curves, and besides, some constitutive law controlling creeping materials.

\subsection{Constitutive Law}

The constitutive law selected for the present study is

$$
\varepsilon_{c}=\varepsilon_{\mathrm{t}}\{1-\exp (-\mathrm{r} \tau)\}+\int_{0}^{\tau} \dot{\varepsilon} \mathrm{d} \tau,
$$

where $\varepsilon_{\mathrm{c}}$ is the creep strain at time $\tau, \varepsilon_{\mathrm{t}}$ is the limiting magnitude of primary creep strains, $r$ is a constant relating to the rate of exhaustion of primary creep, and $\dot{\varepsilon}$ is the creep rate in secondary and tertiary creep. For reference, in such the special case that $\dot{\varepsilon}$ can be regarded as an invariable, Eq. (5) leads to the well-known equation of McVetty-Garofalo ${ }^{10}$

$$
\varepsilon_{\mathrm{c}}=\varepsilon_{\mathrm{t}}\{1-\exp (-\mathrm{r} \tau)\}+\dot{\varepsilon} \tau .
$$

Values of $\varepsilon_{\mathrm{t}}$ and $\mathrm{r}$ depend on applied stress $\sigma$. The measurements by the present authors ${ }^{7)}$ suggested that the stress dependence of the parameters for primary creep can be well approximated in the forms of

$$
\varepsilon_{\mathrm{t}}=\mathrm{D} \sigma+\mathrm{E} \text { and } \mathrm{r}=\mathrm{F} \exp (\mathrm{G} \sigma),
$$

where $D, E, F$ and $G$ are material constants.

For values of $\dot{\varepsilon}$ in Eq. (5), a modification of the term of stress in so-called Norton's power law yields ${ }^{11)}$

$$
\dot{\varepsilon}=\mathrm{H}\{\sigma /(1-\mathrm{I} \omega)\}^{\mathrm{n}},
$$

where $\mathrm{H}, \mathrm{I}$ and $\mathrm{n}$ are material constants. The term $(1-\mathrm{I} \omega)$ can be interpreted to relate to the current cross-sectional areas of damaged materials. Anyway, Eq. (8) expresses that damage accelerates creep deformation through the effect of stress $\sigma /(1-\mathrm{I} \omega)$ intensified by an increase in $\omega$. The constant I varies from 0 to 1 corresponding to the degrees of interactions between macroscopic deformation as a continuum and microscopic damage ${ }^{11}$. For materials the damage of which has no influence on their deformation, the constant I takes the value 0 .

\subsection{Determination of Material Constants}

Each of the material constants $\{A, B, C, \cdots, I, n$, $\mu$ and $\nu\}$ can be determined by fitting the abovecited equations to the data of creep and creeprupture tests.

Strictly speaking, any of the data to be served to determining these constants must be taken under a constant stress throughout creep testing (See the assumption for Eq. (3) in Clause 2.1). Such tests, however, are usually impracticable, and for the time being, we have no choice but to substitute the data of conventional creep tests under a constant tensile load for those under a constant stress.

In the present study, with a view to making a better approximation to the data of constant stress creep tests, a correction was made for the nominal value of the applied stress in constant load creep tests, namely any increasing stress in a creeping specimen under a constant load is featured by its time-average. For example, we regard the time-to-rupture under a constant load to be nearly equal to that under the same "constant stress" as such an averaged stress during creep testing ${ }^{7,12)}$. For the creep parameters of $\varepsilon_{t}$ and $r$ in Eqs. (5)-(7), we had better take the timeaverage of stress only for the stage of primary creep $^{7}$.

Assuming no change in volume and little necking of creeping specimens*, we can estimate such an increase of stress $\sigma$ readily from the data of the corresponding creep curve, viz.

\footnotetext{
* Successive observations of creeping specimens by the authors proved that the 304 steel used in the present study maintained a state of uniform elongation up to about $90 \%$ of the time-to-rupture.
} 


$$
\sigma=\sigma_{\text {nom }}\left(1+\varepsilon_{\text {total }}\right),
$$

where $\sigma_{\text {nom }}$ is the nominal value of the applied stress in creep testing, and $\varepsilon_{\text {total }}$ is the current value of the total strain given by the sum of the instantaneous elastic plastic strain due to the loading and the creep strain.

After correcting the nominal values of stress to the averaged values, the material constants are determined by the following procedures:

a . Fitting of Eq. (1) to creep-rupture data gives $\mathrm{A}$ and $\mathrm{B}$, and then, Eq. (4) determines $\mu$ and $\mathrm{C}(\nu+1)$.

b. Fitting of Eq. (6) to the primary and secondary stages of measured creep curves gives $\varepsilon_{t}$ and $r$ for a specified stress $\sigma$, and then, fitting of Eq. (7) to the given $\varepsilon_{\mathrm{t}}$ and $\mathrm{r}$ versus $\sigma$ yields $\mathrm{D}, \mathrm{E}$, $F$ and $G$.

c. Initially, temporary values are assumed for each of $\mathrm{C}$ (or $\nu$ ), H, I and $\mathrm{n}$, and the time is divided into short intervals. Then, for specified values of $\sigma$, the following numerical operations give the computed creep curves of Eq. (5). Here, $\sigma, \dot{\omega}$ and $\dot{\varepsilon}$ are assumed to remain unchanged during a time interval and to jump stepwise at the start of the succeeding one.

c-0. $\omega, \varepsilon_{\mathrm{c}}$ and time $\tau$ are initialized to be 0 .

$\mathrm{c}-1$. Integration of $\mathrm{Eq}$. (2) over the present time interval gives the increment of $\omega$ during the interval.

$\mathrm{c}^{-2}$. Integration of $\mathrm{Eq}$. (8) gives the increment of the value of the second term in the right side of Eq. (5).

$c-3$. These increments are added to the preceding values.

$c^{-4}$. Equation (5) gives the current value of $\varepsilon_{c}$, and then, addition of this to the measured value of the instantaneous strain due to the loading gives the current value of the total strain.

c-5. $\sigma$ is renewed by calculating Eq. (9).

$\mathrm{c}-6$. Time $\tau$ is updated.

$c-7$. Operations from $c-1$ to $c-6$ are repeated up to the "time-to-rupture" at which the cumulated $\omega$ exceeds the critical value 0.99 . This value is taken instead of the rightful value 1.00 for convenience of using computers (Substitution of 1.00 into $\omega$ in Eq. (2) causes the run-time error of division-by-zero).

Trial and error of the above procedure are reiterated with shifting each value of $\mathrm{C}$ (or $\nu$ ), $\mathrm{H}$, $\mathrm{I}$ and $\mathrm{n}$ bit by bit until we finally find the closest agreement between creep curves computed from Eq. (5) and those measured for all of applied stresses.

The determined values of these material constants are input to the following FEM program.

\subsection{FEM Program and Procedures to Predicting Creep Lifetime}

Needless to say, the stress is the most essential variable which controls the creep damage, and eventually, the creep lifetime.

In the present study, a FEM program was prepared for the computation of stress in creeping welded joints.

The constitutive equation selected for this program is

$$
\left\{\stackrel{o}{\sigma}_{i j}\right\}=\left\{C_{1 j k l}\right\}\left\{D_{k l}\right\},
$$

where $\left\{\dot{\sigma}_{i j}\right\}$ is Jaumann's stress rate, $\left\{\mathrm{C}_{\mathrm{ljk}}\right\}$ is the stress-strain matrix ${ }^{13)},\left\{D_{k 1}\right\}$ is the "rate of deformation (stretch tensor)", and, the subscripts $\mathrm{i}, \mathrm{j}, \mathrm{k}$ and 1 , representing each of the orthogonal coordinate axes, take 1,2 or 3 .

The "principle of virtual work" and the above equation lead to ${ }^{14)}$

$$
\left(\{\mathrm{K}\}+\left\{\mathrm{K}_{G}\right\}\right)\{\dot{\mathrm{u}}\}=\{\dot{\mathrm{f}}\},
$$

where $\{\mathrm{K}\}$ and $\left\{\mathrm{K}_{\mathrm{G}}\right\}$ are the stiffness matrix for infinitesimal deformation and the geometric stiffness matrix, respectively (The full descriptions ${ }^{14)}$ are not inserted for want of space.), while $\{\dot{\mathrm{u}}\}$ and $\{\dot{\mathrm{f}}\}$ are the vectors of the rate-of-change of displacement and nodal force, respectively (Hereafter, any matrix or vector is given in the braces \{\} ).

The program begins with an elastic-plastic analysis, which develops a system of stress $\left\{\sigma_{1 \mathrm{Ij}}\right\}$ due to the initial loading of creep testing.

The data of $\left\{\sigma_{1 j}\right\}$ gives the initial values of the succeeding analysis of creep ${ }^{2}$. Here, once again, we assume for stress, creep rates and the time rates-of-change of the damage variable to remain constant during the short interval of time and to change abruptly at the boundaries of intervals. The procedures of the analysis are as follows:

1) Initializing time $t$ to be 0 , and also, creep strain $\left\{\varepsilon_{\mathrm{cij}}\right\}$, its equivalent strain $\varepsilon_{\mathrm{ceq}}$ and damage variables $\omega$ to be 0 for all the finite elements (integration points),

2) Converting stress $\left\{\sigma_{i j}\right\}$ into von Mises' equivalent stress $\sigma_{\mathrm{eq}}$ and the maximum principal stress $\sigma_{\max }$

3) Determining the creep parameters of $\varepsilon_{t}$ and $r$ by substituting the above $\sigma_{\mathrm{eq}}$ into $\sigma$ in Eq. (7),

4) Solving Eq. (5) for pseudo time $\tau$, which is different one from the "time $t$ " in 1), as computing the right side of Eq. (5) by almost the same procedure as that of $\mathrm{c}$. in Clause 2.3 (No renewal of $\sigma$ is required.),

5) Calculating the rates of the equivalent strain of creep $\varepsilon_{\text {ceq }}$ for the pseudo time $\tau$ from

$$
\dot{\varepsilon}_{6 c e q}=r \varepsilon_{t} \exp (-r \tau)+H\left\{\sigma_{e q} /(1-I \omega)\right\}^{n},
$$

6) Finding the time increment $\Delta t$, during which 
the increment of the equivalent strain of creep $\Delta \varepsilon_{\text {ceq }}=\dot{\varepsilon}_{\text {ceq }} \Delta$ t does not exceed 0.05 of the elastic strain $\sigma_{\text {eq }} / \mathrm{E}$ (where $\mathrm{E}$ is Young's modulus) in any of finite elements (or at any of integration points) ${ }^{15}$,

7) Distributing $\Delta \varepsilon_{\text {ceq }}$ to the increment of creep strain $\left\{\Delta \varepsilon_{\mathrm{clj}}\right\}$ in proportion to the current deviatoric stress (von Mises' flow rule),

8) Adding $\left\{\Delta \varepsilon_{\mathrm{clj}}\right\}$ to the preceding $\left\{\varepsilon_{\mathrm{clj}}\right\}$,

9) Determining new $\varepsilon_{\text {ceq }}$ in conformity to some "strain hardening rule" for creep ${ }^{16)}$,

10) Computing the increment of stress $\left\{\Delta \sigma_{i j}\right\}$ and the displacement of nodal points $\{\Delta \mathrm{u}\}$ considering $\left\{\Delta \varepsilon_{\mathrm{cl}\}}\right\}$ as an "initial strain" imposed"),

11) Updating stress $\left\{\sigma_{\mathrm{lj}}\right\}$ by $\left\{\Delta \sigma_{\mathrm{ij}}\right\}^{14)}$,

12) Correcting unbalanced residual force to be $\{0\}$, and

13) Moving coordinates of nodal points by $\{\Delta \mathrm{u}\}$ (Updated Lagrangean formulation).

Now, the program comes to the procedure of cumulating the damage variable. Here, we have to take either the equivalent stress $\sigma_{\mathrm{eq}}$ or the maximum principal stress $\sigma_{\max }$ as the criterion of stress controlling creep damage. For example, in case of nickel-chromium alloys, $\sigma_{\mathrm{eq}}$ is dominant ${ }^{17}$. Then,

14) Determining the time rates-of-change of the damage variable $\omega$ by substituting $\sigma_{\text {eq }}$ or $\sigma_{\max }$ into $\sigma$ in Eq. (2), and then, cumulating the damage variables $\omega$ by their increment $\Delta \omega=\dot{\omega} \Delta \mathrm{t}$,

15) Clearing Young's modulus $\mathrm{E}$ to 0 for the finite elements $\omega$ of which exceeds 0.99 by considering that such elements have been so damaged that they have lost their elasticity already, and

16) Setting time $t$ ahead by $\Delta t$, and returning to the procedure of 2).

Reiterations of these procedures and the resulting increase in the number of damaged elements make the time increment $\Delta t$ determined by the procedure of 6) gradually small. The reason for this is due to the rapidly increased stress with the increase in damaged elements. The increment $\Delta t$ is reducing unlimitedly toward 0 , and after all, the time $t$ converges substantially into a fixed value.

We regard such $\mathrm{t}$ as the creep lifetime and stop computing.

\section{Preparation of Welded Joint and Proce- dures of Creep Tests}

The accuracy of computations in comparison with measurements depends considerably on the accuracy of the basic data used for determining material constants. For the computations of creeping welded joints, referring to a published data often raises a question whether the data is chosen carefully or not, since creep properties of materials are essentially structure-sensitive, and consequently, sensitive to the procedural data of welding.

Another problem in testing the accuracy of computations is with few analytical solutions which are to be reference standards for checking computations.

These circumstances require new acquisition of data for the very thing of the welded joint to be analyzed.

Thus, in the present study, a butt-welded joint of $50 \mathrm{~mm}$ thick Type 304 stainless steel $(.05 \% \mathrm{C}$, $9 \% \mathrm{Ni}$ and $19 \% \mathrm{Cr}$ ) was prepared by SAW with depositing a 308 wire $(.05 \% \mathrm{C}, 10 \% \mathrm{Ni}, 20 \% \mathrm{Cr}$ and $.1 \% \mathrm{~V})$. Its cross section is shown in Fig. 1. The less etched zone, about $3.5 \mathrm{~mm}$ wide from the bond line toward the base metal, is regarded as the "heat-affected zone (HAZ)".

After shaving the weld reinforcement, specimens for creep testing were cut out of the welded joint as shown in Fig. 2.

Specimens WM1, WM2 and WM3 are "allweld-metal" specimens of $6 \mathrm{~mm}$ in diameter. They were machined out at the $1 / 4^{-}$, mid- and $3 / 4$-thickness of the plate, respectively. The data from them, which is considered to represent for

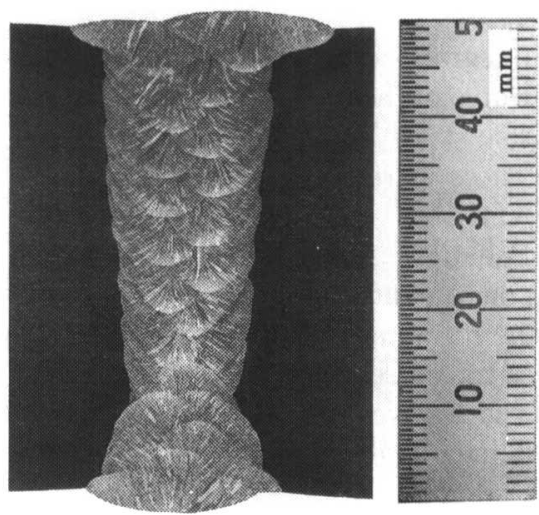

Fig. 1 Cross section of joint.

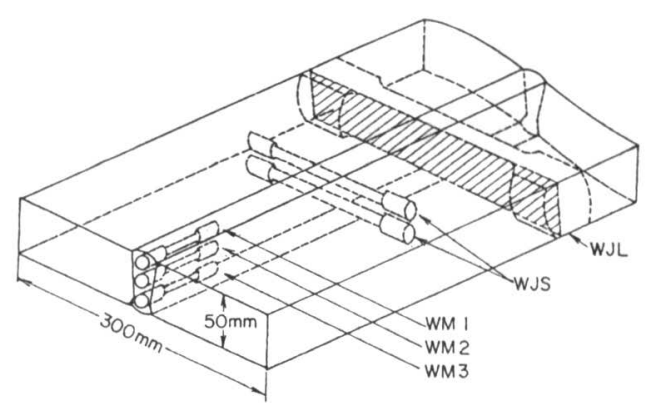

Fig. 2 Location of sampling specimens. 
that of the upper, middle and lower third of the weld metal zone, respectively, was served to the determination of their material constants.

Specimen WJL is a "joint" specimen with a rectangular cross section of the full thickness of the base metal with $10 \mathrm{~mm}$ in width and the gauge length of $160 \mathrm{~mm}$. In the present study, we chose its creep behavior as the subject of computation.

Another "joint" specimen WJS with $10 \mathrm{~mm}$ in diameter was used to estimate the plastic and creep strain of HAZ.

We can estimate these strains by assuming no change in volume, and additionally, an almost uniaxial state of stress in the $3.5 \mathrm{~mm}$ thick disklike HAZ forming part of WJS, viz.

$$
\mathrm{d}_{0}^{2}=\left(1+\varepsilon_{\text {inelas }}\right) \mathrm{d}^{2} \text {, }
$$

where $d_{0}$ and $d$ are the diameters of the part of HAZ before and after loading, respectively, and $\varepsilon_{\text {inelas }}$ is the plastic (or creep) strain.

The diameter of the creeping $\mathrm{HAZ}$ was mea sured with repeating the sequence of testing, interruption and measuring it.

Besides, the "base metal" specimen BM with 10 $\mathrm{mm}$ in diameter was prepared.

All of these specimens were subjected to creep tests at $823 \mathrm{~K}\left(550^{\circ} \mathrm{C}\right)$ under applied stress of 200 to $300 \mathrm{MPa}$.

\section{Test Results}

\subsection{Short-Time Tensile Properties}

With a view to determining the stress-strain matrix $\left\{\mathrm{C}_{\mathrm{ijkl}}\right\}$ in Clause 2.4, short-time tension tests at $823 \mathrm{~K}$ were made for the base metal BM

Table 1 Material constants determined from short-time tension tests at $823 \mathrm{~K}$.

\begin{tabular}{lrrrrc}
\hline & $\begin{array}{c}\sigma \\
(\mathrm{MPa})\end{array}$ & $\begin{array}{c}\mathrm{E} \\
(\mathrm{GPa})\end{array}$ & $\mathrm{c}$ & $\mathrm{a}$ & $\mathrm{m}$ \\
\cline { 2 - 6 } BM & 126.3 & 177.3 & 1006 & 0.0170 & 0.5093 \\
WM1 & 243.2 & 111.4 & 650.3 & 0.0238 & 0.2631 \\
WM2 & 276.1 & 112.7 & 595.2 & 0.0198 & 0.1959 \\
WM3 & 234.4 & 97.5 & 692.2 & 0.0320 & 0.3146 \\
HAZ & 120.3 & 177.3 & 586.7 & 0.00001 & 0.1376
\end{tabular}

(Note) The values of $c$ and a are determined for the units of stress in MPa and strain in $\mathrm{mm} / \mathrm{mm}$, respectively.

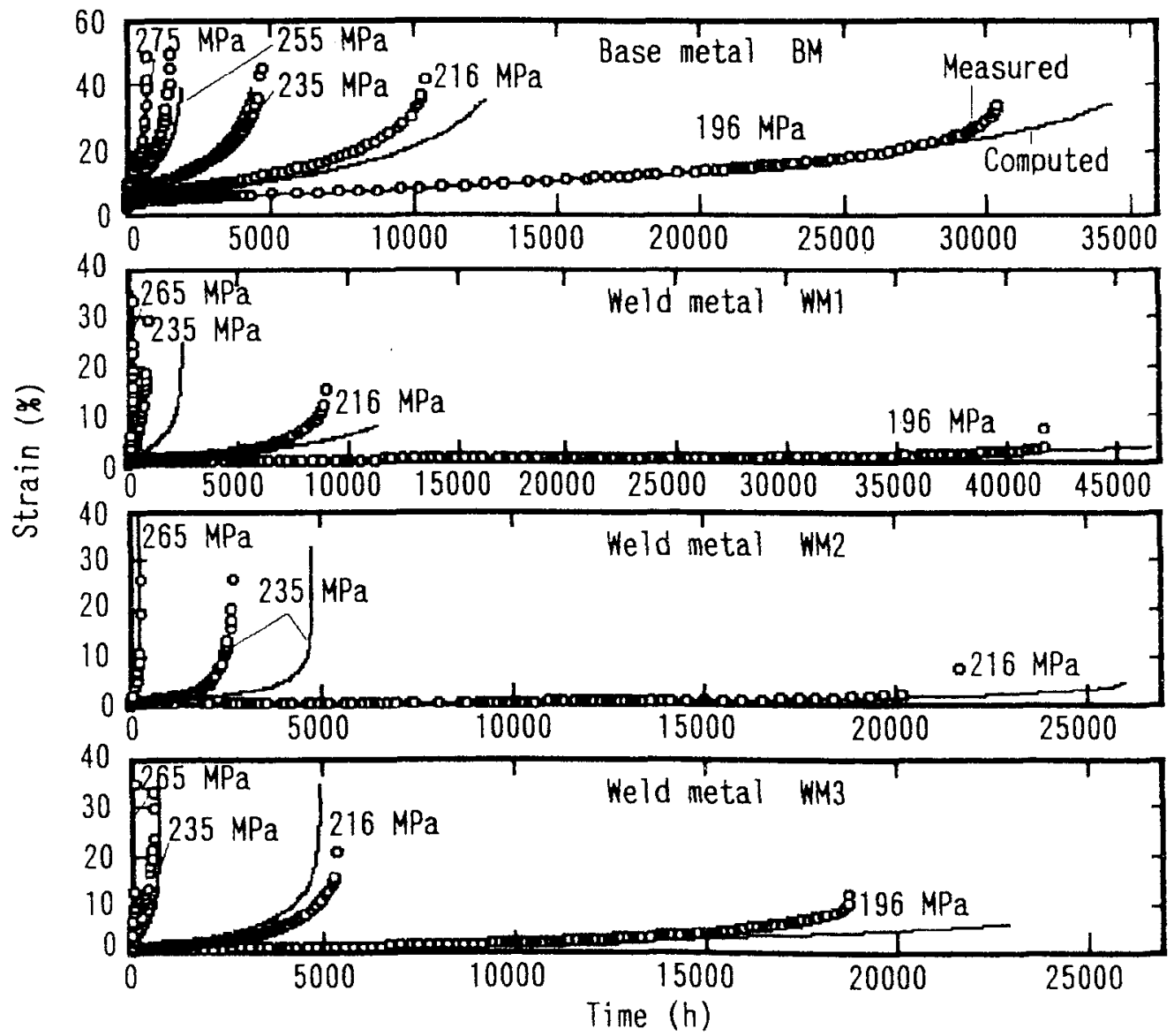

Fig. 3 Creep curves of specimens BM and WM1-3 (Plots: Measured, Solid lines : Computed). 
and the weld metals WM1 -3 . For their measured curves of stress $\sigma$ versus strain $\varepsilon$, an experimental bi-linear formula was selected, i.e., for $\sigma$ under the yield stress $\sigma_{y}$,

$$
\sigma=\mathrm{E} \varepsilon \text {, }
$$

while for $\sigma$ over $\sigma_{\mathrm{y}}$,

$$
\sigma=c\left(a+\varepsilon_{p}\right)^{\mathrm{m}}
$$

where $\mathbf{E}$ is the Young's modulus, $\varepsilon_{\mathrm{p}}$ is the plastic strain, and, c, a and $\mathrm{m}$ are material constants. Table 1 gives the values of $\sigma_{y}, E, c, a$ and $m$ determined for each of the base metal, weld metals and $\mathrm{HAZ}$.

For the HAZ, because of technical difficulties, we could not prepare any specimen, the section of which was of sufficient homogeneity. So, an

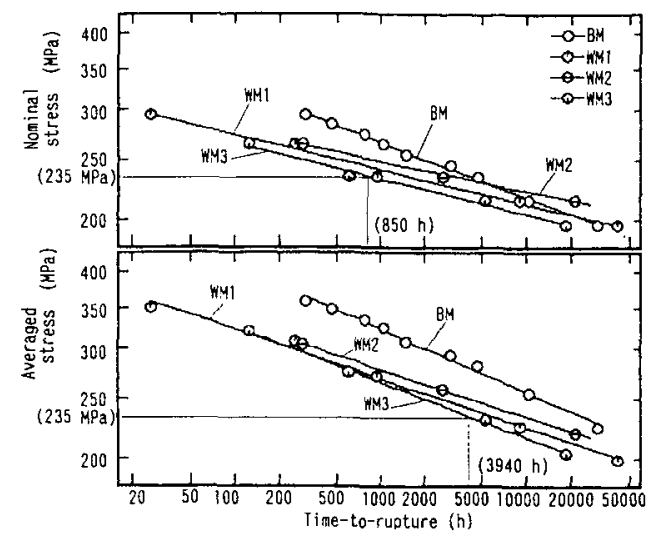

Fig. 4 Creep-rupture curves arranged by nominal stress (upper) and those by averaged stress during creep testing (lower) for specimens BM and WM1-3 (The level lines of $235 \mathrm{MPa}$ exemplify the discrepancy between the upper and lower diagrams). estimation was made from the data of specimen WJS (See Sec. 3). The value of Young's modulus for the HAZ was assumed to be identical to that of the base metal.

Besides, for all of them, Poisson's ratio in instantaneous elastic deformation and in creep was assumed to be the same ${ }^{2)}$ and to be $0.33^{18)}$.

\subsection{Creep and Creep-Rupture Properties}

Figure 3 shows some of creep curves measured for the base metal BM and weld metals WM1-3. The local-variability as is seen for the curves of WM1-3 under the same applied stress is considered to result from their differences in thermal, stress and strain histories during multi-layer welding.

Figure 4 compares the conventional creeprupture curves by the nominal stress (upper) and those by the averaged stress during creep testing (lower) for the base metal BM and weld metals WM1-3. Each yields a quite different estimate of the time-to-rupture from other. For example, in the case of WM3 under $235 \mathrm{MPa}$, the upper diagram shows $850 \mathrm{~h}$, while the lower one gives 3940 $h$. In the present study, according to the prearranged course (See Clause 2.3), the lower one was served to determine the material constants.

The values determined for all of the material constants are summarized in Table 2.

With regard to HAZ, for the reason mentioned already, we have no detailed data but only a rough estimate of time versus creep strain. From such circumstances, we assumed no primary creep of HAZ. In addition, no creep damage in $\mathrm{HAZ}$ was considered to develop into its complete failure, since any instance that a welded joint of austenitic steel ruptured at its $\mathrm{HAZ}$ was not

\begin{tabular}{|c|c|c|c|c|c|c|c|c|}
\hline \multirow{3}{*}{$\begin{array}{l}\text { BM } \\
\text { WM1 } \\
\text { WM2 } \\
\text { WM3 }\end{array}$} & A & $B$ & & C & $\mu$ & $\nu$ & \multicolumn{2}{|c|}{$\begin{array}{c}D \\
(\% / \mathrm{MPa})\end{array}$} \\
\hline & $\begin{array}{l}-1.00 \times 10^{-1} \\
-7.85 \times 10^{-2} \\
-7.46 \times 10^{-2} \\
-8.81 \times 10^{-2}\end{array}$ & $\begin{array}{l}2.81 \\
2.67 \\
2.67 \\
2.69 \\
\end{array}$ & $\begin{array}{l}9.95 \\
8.8 \\
8.95 \\
1.4\end{array}$ & $\begin{array}{l}9 \times 10^{-30} \\
37 \times 10^{-35} \\
99 \times 10^{-37} \\
3 \times 10^{-31}\end{array}$ & $\begin{array}{l}9.95 \\
12.7 \\
13.4 \\
11.4\end{array}$ & $\begin{array}{l}9.72 \\
0.189 \\
0.941 \\
1.07\end{array}$ & $\begin{array}{l}-1.0 \\
-3.9 \\
-2.1 \\
-6.5\end{array}$ & $\begin{array}{l}5 \times 10^{-2} \\
7 \times 10^{-3} \\
1 \times 10^{-3} \\
4 \times 10^{-3}\end{array}$ \\
\hline & $\underset{(y)}{E}$ & $\mathrm{~F}$ & & $\mathrm{G}$ & \multicolumn{2}{|c|}{$\mathrm{H}$} & $\mathrm{n}$ & I \\
\hline $\begin{array}{l}\text { BM } \\
\text { WM1 } \\
\text { WM2 } \\
\text { WM3 } \\
\text { HAZ } \\
\text { HAZ }\end{array}$ & $\begin{array}{l}3.85 \\
1.29 \\
0.674 \\
2.07 \\
\quad \text { Stres } \\
\text { Stres }\end{array}$ & $\begin{array}{l}1.70 \times 10^{-} \\
5.71 \times 10^{-} \\
2.78 \times 10^{-} \\
2.08 \times 10^{-} \\
\text {ss } \leqq 20 \\
\text { s } \leqq 20\end{array}$ & $\begin{array}{r}-8 \\
-8 \\
-15 \\
-\quad 9 \\
00 \\
00\end{array}$ & $\begin{array}{l}5.33 \times 10^{-2} \\
5.99 \times 10^{-2} \\
1.31 \times 10^{-1} \\
7.60 \times 10^{-2} \\
\mathrm{MPa} \\
\mathrm{MPa} *\end{array}$ & \multicolumn{2}{|c|}{$\begin{array}{l}6.16 \times 10^{-28} \\
1.61 \times 10^{-52} \\
2.05 \times 10^{-75} \\
4.88 \times 10^{-53} \\
1.06 \times 10^{-51} \\
0\end{array}$} & $\begin{array}{l}10.2 \\
20.6 \\
30.0 \\
21.1 \\
20.1\end{array}$ & $\begin{array}{l}0.00 \\
0.04 \\
0.10 \\
0.04\end{array}$ \\
\hline
\end{tabular}

Table 2 Material constants determined from creep and creep-rupture tests at $823 \mathrm{~K}$.

(Note) The values of $A, B, C, F, G$ and $H$ are determined for the *) units of stress in MPa, time in $h$ and strain in $\%$. *) No measurable creep was produced 7) 
found so far as we surveyed. Thus, the cumulation of the damage variable was not made for the HAZ.

The creep curves computed by using the constants in Table 2 are also shown in Fig. 3. Computations agree relatively well with measurements except for some of the curves of the weld metals WM1 and 2.

\section{Comparison Between Computations and Measurements}

Figure 5 shows the mesh divisions of the twoand three-dimensional model for the joint specimen WJL into finite elements. The divisions are made only of the half side of the modeled WJL by taking its substantial symmetry into account.

The specimen WJL, $10 \mathrm{~mm}$ in thickness, can be regarded to be "thin" in comparison with $50 \mathrm{~mm}$ in width. Accordingly, the two-dimensional model was assumed to be in a state of "plane stress". The finite elements used are of the quadri-lateral with 4 points of integration and of the hexahedron with 8 points for the two- and three-dimensional model, respectively. Any computation for the three-dimensional model required the technique of "selectively reduced integration ${ }^{19) "}$ in order to overcome severe "locking phenomena" of computations.

Figure 6 shows the computations of the damage variable being cumulated with time (upper) and the corresponding creep curves (lower) for an applied stress of $265 \mathrm{MPa}$. Each curve of cumulated damage is given only for the most damaged point $\mathrm{a}, \mathrm{b}$ or $\mathrm{c}$ (See Fig. 5) under the specified stress criterion of equivalent stress or maximum principal stress. In every case, the time $\mathrm{t}$ in the FEM stated in Clause 2.4 nearly stopped just after its curve of cumulated damage crossed over the level of $\omega=0.99$, and thus, we approximated the time of such crossing as the computed lifetime of WJL under each of the criteria.

For comparison, the final lifetime and the creep curve of WJL measured under the stress of 265 $\mathrm{MPa}$ are also shown in Fig. 6. It is evident that, for both of the lifetime and the creep curve, the criterion of equivalent stress results in a closer agreement between computations and measure-

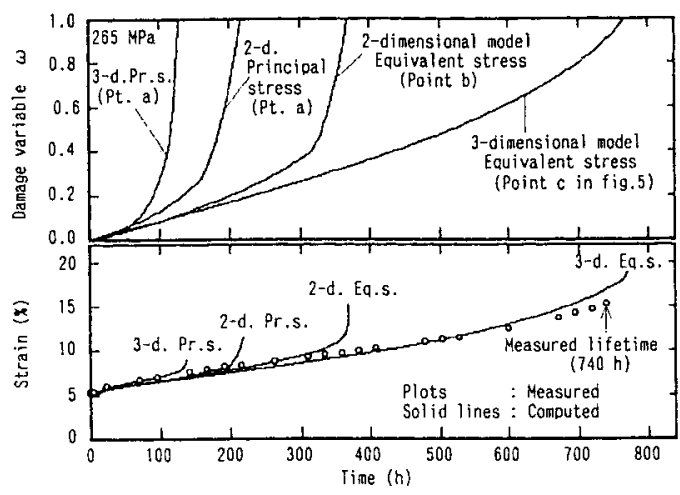

Fig. 6 Damage variable being cumulated with time (upper) and creep curves (lower) of specimen WJL for $265 \mathrm{MPa}$.

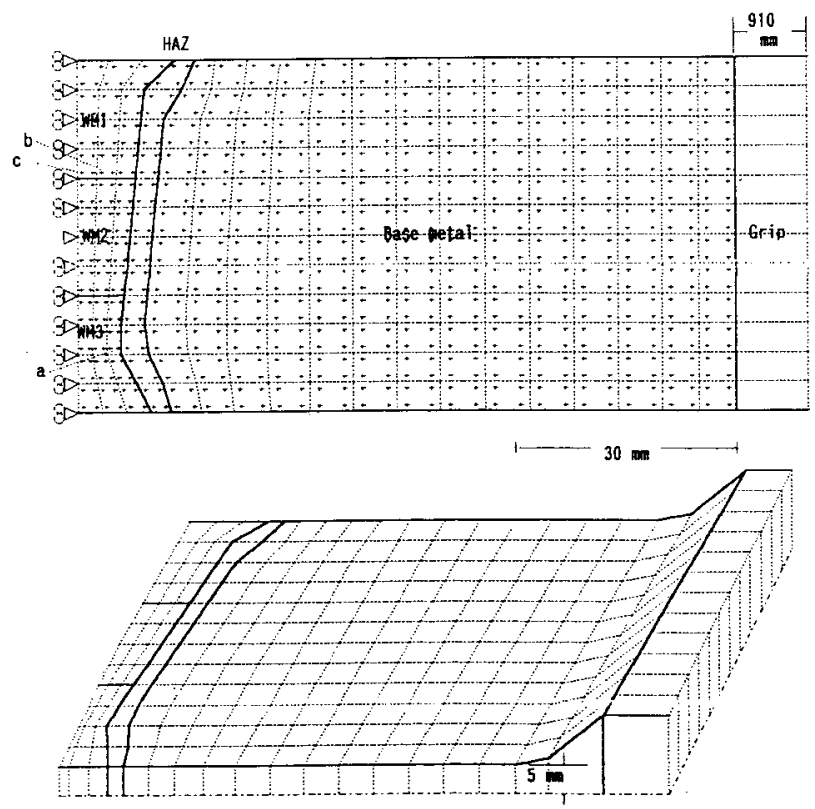

Fig. 5 Mesh divisions for joint specimen WJL. 


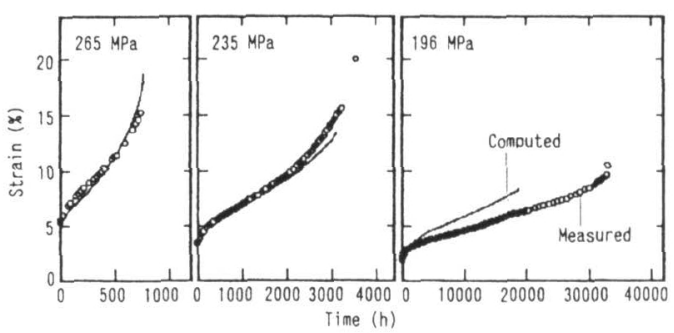

Fig. 7 Computed and measured creep curves of specimen WJL.

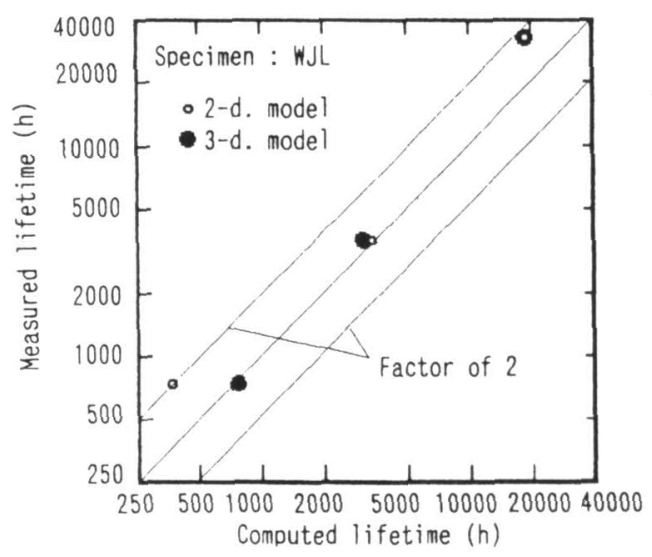

Fig. 8 Lifetime of specimen WJL computed vs. that measured.

ments than that of principal stress. Thus, hereafter, we take the equivalent stress as the criterion of stress controlling creep damage.

Figure 7 compares the creep curves of WJL computed for the three-dimensional model and those measured. Only in the case of $196 \mathrm{MPa}$, the agreement seems to be unsatisfactory. The reason may be due to the lack of long-time creep data. Under low stresses, such as $196 \mathrm{MPa}$, it takes more than tens of thousands of hours to complete creep tests. For the time being, we have merely several of such long-time data. Thus, the material constants, being determined under the above circumstances, are considered not to be sufficiently accurate in extrapolating them toward low stresses. We are still trying to obtain additional long-time data.

Nevertheless, the creep lifetime of WJL computed for both of the two- and threedimensional models, as is shown in Fig. 8, correlates to that measured with an accuracy surely better than the so-called "factor of two" (which means that each is from one half to two times of other). This can be recognized as a meaningful engineering accuracy in view of the present stateof-the-art of predicting creep lifetime.

For the three-dimensional model of WJL, com-

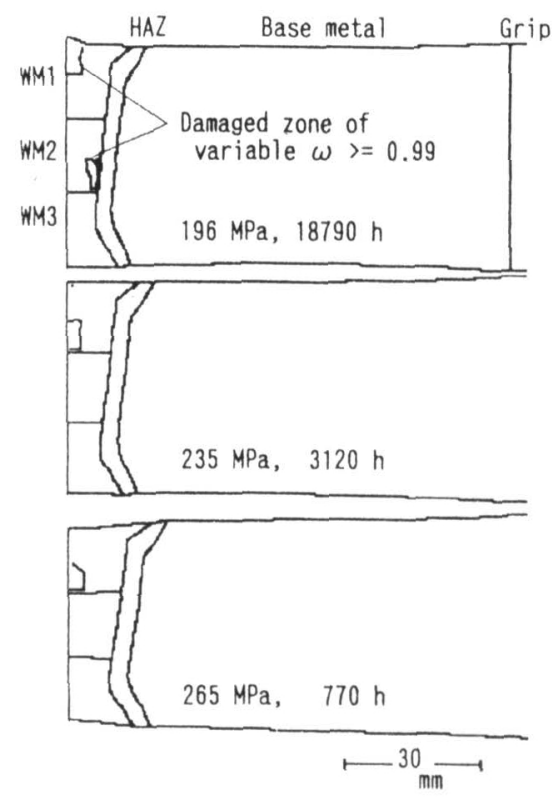

Fig. 9 Zones of cumulated damage variable having exceeded 0.99 finally in specimen WJL.

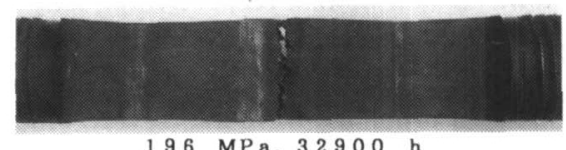

$196 \mathrm{MPa}, 32900 \mathrm{~h}$

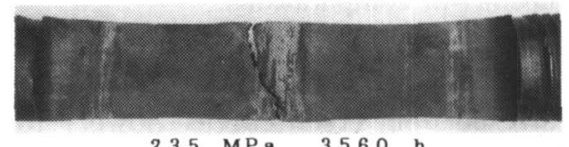

$235 \mathrm{MPa}, \quad 3560 \mathrm{~h}$

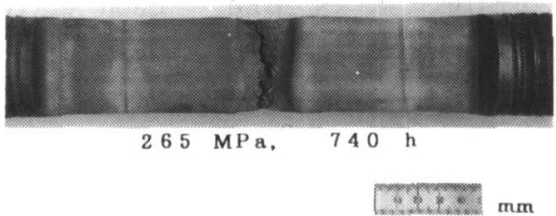

Fig. 10 Creep-ruptured specimens WJL.

pletely damaged zones in which the cumulated damage variable $\omega$ finally exceeded the critical value of 0.99 are shown in Fig. 9. The figure predicts that the joint specimen WJL may be ruptured at its weld metal zone under all of the applied stresses specified.

Figure 10 shows the creep-ruptured specimens of WJL. Under the same applied stresses as those in Fig. 9, each of the specimens is ruptured at its weld metal zone. Thus, the above prediction of locating the rupture entirely agrees to the fact.

\section{Concluding Remark}

A finite element analysis incorporating a state variable for creep damage predicted the creep lifetime of a welded joint of Type 304 stainless 
steel within the factor of two (one half to two times) of that measured.

To realize higher accuracy, creep data of longer-time, or some new approach of extrapolating data instead, seems to be essential. Further refinement of creep laws also may be necessary.

\section{References}

1) See for example, I. Okane and M. Inagaki : Creep Rupture Properties of Welded Joints of Quenched and Tempered High Strength Steel, Trans. Nat. Res. Inst. Metals, 13-1 (1971), 14-23.

2) O.C. Zienkiewicz, M. Watson and I.P. King: A Numerical Method of Visco.Elastic Stress Analysis, Int. J. mech. Sci., 10 (1968), 807-827.

3) W.H.Sutherland: AXICRP-Finite Element Computer Code for Creep Analysis of Plane Stress, Plane Strain and Axisymmetric Bodies, Nuclear Engineering and Design, 11 (1970), 269-285.

4) F. Roode, C.F.Etienne and O.van Rossum: Stress and Strain Analyses for Creep and Plasticity of Welded Joints in AISI 316, Proc. of Int. Conf. on Engineering Aspects of Creep (Vol. II), I Mech E Conf. Pub. (1980), 123-129.

5) R.J. Browne, B.J. Cane, J.D. Parker and D.J. Walters : Creep Failure Analysis of Butt Welded Tubes, Recent Advances in Creep and Fracture of Engineering Materials and Structures, Pineridge Press, Swansea, UK (1981), 645-657.

6) M.J. Manjoine: Creep-Rupture Behavior of Weldments, Weld. J., 61-2 (1982), 50s-57s.

7) Y. Muramatsu, J. Kinugawa, Y. Monma and M. Yamazaki : Creep Behaviour and FEM Analysis of Welded Joints of 304 Stainless Steel, Proc. of 2nd Int. Conf. on Computer Technology in Welding, TWI (1988), Paper 3, or J. Kinugawa, et al.: Computation for Creep Deformation of Welded Joint of 304 Stainless Steel by Using Finite Element Method, Q. J. Jpn.
Weld. Soc., 7-1 (1989), 117-124 (in Japanese).

8) L.M. Kachanov: On the Rupture Time under the Condition of Creep, Izv. Akad. Nauk SSSR, Otd. Tekh. Nauk, No. 8 (1958), 26-31 (in Russian).

9) F.K.G. Odqvist: Mathematical Theory of Creep and Creep Rupture, Oxford at the Clarendon Press (1966), 12.

10) See for example, F. Garofalo: Fundamentals of Creep and Creep-Rupture in Metals, The MacMillan Co. (1965), 12.

11) S. Murakami and N. Ohno: A Continuum Theory of Creep and Creep Damage, Proc. of 3rd IUTAM Sympo. on Creep in Structures, Springer-Verlag (1981), 422-444.

12) C.W. Lawton: True Stress Versus True Strain Isochronous Curves, The Generation of Isochronous Stress-Strain Curves, ASME (1972), 49-54.

13) K. Washizu et al. (Eds.) : Yugen-Yoso-Ho Handbook II OyoHen (Handbook of Finite Element Method II Applications), Baifu-Kan Co. (1981), 195196 (in Japanese).

14) Ref. 13), 278-282.

15) Ref. 13), 232.

16) See for example, S. Murakami and N. Ohno: A Constitutive Equation of Creep Based on the Concept of a Creep Hardening Surface, Int. J. Solids Structures, 18-7 (1982), 597-609.

17) See for example, D.R. Hayhurst: Creep Rupture under Multi-Axial States of Stress, J. Mech. Phys. Solids, 20 (1972), 381-390.

18) A. Sather: Ultrasonic Buffer-Rod Technique for the High-Temperature Measurement of the Elastic Moduli of Short Specimens, J. Acous. Soc. Amer., 43 -6 (1968), 1291-1294.

19) K. Washizu et al. (Eds.) : Yugen-Yoso-Ho Handbook I Kiso Hen (Handbook of Finite Element Method I Fundamentals), Baifu-Kan Co. (1981), 253255 (in Japanese). 